\title{
Further details concerning the Darwin-Wallace presentation to the Linnean Society in 1858, including its submission on 1 July, not 30 June
}

\author{
Derek Partridge
}

Emeritus Professor, Department of Computer Science, University of Exeter, Exeter, UK

\begin{abstract}
Evidence from the Linnean Society's ledger of papers received in 1858 points to 1 July as the date of submission of the DarwinWallace papers for the famous meeting of the same evening. It has been widely assumed, and repeatedly stated, that the submission was on 30 June. but this article shows that this seems to be a wrong assumption. Acceptance of this later submission date also provides an explanation of the 'oddities' in the letter of transmittal. In turn, this reading implies further details about the separate roles of Hooker and Lyell in the crucial 13 days before the meeting.
\end{abstract}

\section{ARTICLE HISTORY}

Received 14 April 2015

Accepted 2 September 2015

Online 13 November 2015

\section{KEYWORDS}

Evolution; Darwin; Wallace; Hooker; Lyell; Linnean Society; natural selection

The Minutes of the 'Special Meeting' of the Linnean Society held on the evening of 1 July 1858 records the first item of scientific business as the reading of a letter of transmittal from Sir Charles Lyell and Joseph Hooker. Their letter introduces three scientific contributions to be read: first, an 'extract from a MS. work' of Charles Darwin's; second, an 'abstract of a letter' from Darwin to Asa Gray; and finally, an 'essay' by Alfred Russel Wallace. Five further papers were subsequently read at this meeting.

The transmittal letter is dated 30 June, and this seems to be the single item of evidence that is taken as indicating 30 June as the submission date for the package of the letter and the three 'papers' listed above. This date, however, is the date that the letter was written which is, of course, not necessarily the same as the date in which it was delivered to the Linnean Society. In addition, modern practice, which would mark same-day submission as most unusual if not impossible, may provide unconscious reinforcement of this interpretation.

At the time of this meeting the Society maintained a ledger within which were recorded (by the Society's Librarian?) the dates that papers were received, were read, and what was subsequently done with them - for example, the date they were sent to the printer for publication. In addition, each entry was numbered consecutively and other information such as author, title and by whom the paper was communicated was often entered. 
In mid-1858 we find the entries numbered 1246, 1247 and 1248 to be Darwin's 'extract', Darwin's 'letter' and Wallace's paper, respectively. All three are dated in the 'received' column as 1 July. It was, perhaps, common practice for the Librarian to accumulate papers received and to enter them into the ledger periodically as a batch. So the date entered could be the date of entry rather than the date of receipt.

\begin{tabular}{|c|c|c|c|c|c|c|}
\hline & & & PRESENTED & & & HOW DISPOSED \\
\hline NUMBER & RECEIVED & AUTHOR & BY & SUBJECT & READ & OF \\
\hline 1243 & $\begin{array}{l}\text { 2nd June } \\
1858\end{array}$ & Welwitsch & Saunders(?) & $\begin{array}{l}\text { Letter on the vegetation } \\
\text { of Angola }\end{array}$ & 1st July 1858 & $\begin{array}{l}\text { To be printed in } \\
\text { Journal July } 28 / 58\end{array}$ \\
\hline 1244 & $\begin{array}{l}\text { 26th May } \\
1858\end{array}$ & Hilgard(?) & Seemann & On ?? Affinities & $\begin{array}{l}\text { 17th March } \\
1859\end{array}$ & $\begin{array}{l}\text { Not to be printed } \\
\text { April } 7 / 59\end{array}$ \\
\hline 1245 & $\begin{array}{l}\text { 13th April } \\
1858\end{array}$ & $\begin{array}{l}\text { Hanbury } \\
\text { (?) }\end{array}$ & & On ?? from China & 15th April 1858 & $\begin{array}{l}\text { To be printed in } \\
\text { Journal June } 17 / 58\end{array}$ \\
\hline 1246 & $\begin{array}{r}\text { 1st July } \\
1858\end{array}$ & Darwin & & Extract from a work ... & 1st July 1858 & $D^{\circ} D^{\circ}$ July $28 / 58$ \\
\hline 1247 & , ' & Darwin & & Letter to Dr Asa Gray ... & $D^{\circ}$ & $D^{\circ} D^{\circ} D^{\circ}$ \\
\hline 1248 & $\prime \prime$ & Wallace & $\begin{array}{l}\text { Lyell \& } \\
\text { Hooker }\end{array}$ & $\begin{array}{l}\text { On the tendency of } \\
\text { varieties ... }\end{array}$ & $D^{\circ}$ & $D^{\circ} D^{\circ} D^{\circ}$ \\
\hline 1249 & $1 '$ & Dyster & & On the organization ... & $D^{\circ}$ & $\begin{array}{l}\text { To be printed in ?? } \\
\text { July } 28 / 58\end{array}$ \\
\hline 1250 & 1, & Seemann & & $\begin{array}{l}\text { On Hanburya a new } \\
\text { genus ... }\end{array}$ & $D^{\circ}$ & \\
\hline 1251 & $1 '$ & Bentham & & Notes on British Botany & $\begin{array}{l}\text { 4th November } \\
\text { ?? } 1858\end{array}$ & $\begin{array}{l}\text { To be printed in } \\
\text { Journal March } 3 / \\
59\end{array}$ \\
\hline 1252 & $\begin{array}{l}\text { 2nd August } \\
1858\end{array}$ & Mitten & & $? ? ?$ & $\begin{array}{l}\text { 17th March?? } \\
1859\end{array}$ & $D^{\circ} D^{\circ}$ April 7/59 \\
\hline
\end{tabular}

However, as the transcription presented above reveals, the immediately preceding entries, numbered 1243, 1244 and 1245, are dated in the 'received' column, 2 June, 26 May and 13 April, respectively - i.e. in reverse date order! Assuming that the paper numbers were assigned as each paper was entered into the ledger (and they run in an unbroken sequence, top to bottom of each page, through the 7 years surveyed), the date recorded cannot be the date entered. This leaves true date received as the only plausible candidate for the date in the 'received' column if the recording was systematic and accurate.

In order to shed light on the ledger-entry procedures and the quality of data entry, all entries for a 7-year period surrounding 1 July 1858 were analysed in detail. The period chosen was identified as the longest relevant period in which all three major officers - Thomas Bell, President; John Joseph Bennett, Secretary; and Richard Kippist, Librarian - were unchanged in post. We have the expectation that the procedures in operation were stable throughout these 7 years. The period is 24 May 1853, when Bell was elected President, until 24 May 1860, when Bennett resigned as Secretary. Kippist, the Librarian, who we assume wrote the ledger entries, was in post from 1842 until 1880 (Gage and Stearn 1988).

This period begins with the paper numbered 1092, recorded as 'received' and 'read' on 7 June 1853, and it terminates with paper 1347 recorded as 'received' on 24 May 1860 and 'read' on 7 June 1860. With just one entry (1333) crossed out and one entry (1149a) inserted between entries 1149 and 1150, this continuous sequence gives us 256 entries to explore. 
Inspection of the dates recorded reveals only four entries for which the dates 'received', 'read' and 'disposed-of' are not in chronological order. Only one of the four (1311) is a simple sequence of unmodified dates. Our entries of interest, as transcribed above, are all simple, single-date entries that have not been modified. Similarly, the general complication introduced by papers listed with two or three 'read' dates (six entries), and papers entered with crossing out and date overwriting (fewer than 10 entries) are both small scale, and do not impinge on the entries around 1 July 1858.

This necessarily somewhat cursory general analysis does suggest that a fairly smooth procedure of paper receipt, ledger entry and subsequent processing (i.e. when read, and when and how disposed of is supported most of the time. If we include small batch entry (invariably consistent with ledger entry on a meeting date) as a part of the process this simple procedure appears to operate uninterrupted throughout the 7 years. Two minor challenges to this assumption evident in the ledger are the two entries seemingly about 3 months out of order (entries 1327 and 1329), and the single inserted entry 1149a.

With respect to our major concern, 'received' dates, 10 are missing and a further three are missing the day of the month. It may be of significance that for two of the three incomplete 'received' dates, and for one of the missing 'received' dates, the Secretary is recorded as 'communicating' or 'presenting' the associated paper (the President is involved with another of the missing 'received' dates). Such explicit omission of dates and date details can be interpreted as further evidence of precision in the recorded 'received' dates. Unknown 'received' dates were not 'manufactured' or simply filled in with 'date of entry', as with unknown date details, they were simply omitted.

This analysis, which is suggestive of a less than urgent approach to data entry but with no indications of significant imprecision, strongly supports the recorded 'received' date of 1 July as the true date of submission of the Darwin-Wallace papers, not 30 June as is often stated (Gage and Stearn 1988; Desmond and Moore 1992; Browne 2002; Glaubrecht 2013; Costa 2014).

We also note that 136 papers (more than 50\%) were submitted on the day that they were read. Indeed, three other papers were submitted on 1 July to be read that same day. So there was nothing at all unusual in the Darwin-Wallace package being submitted on 1 July.

This in itself is a relatively minor reinterpretation of history, but, when rolled backwards in time into the obscurity of the crucial 13 days that separated Darwin's frantic letter to Lyell on 18 June and the 1 July presentation, it does support substantial further informative speculation. In particular, it offers an explanation for 'oddities' in the letter of transmittal which can then be further extended to suggest the precise roles of Lyell and Hooker in the famous 'delicate arrangement' (Brackman 1980).

The transmittal letter (Darwin and Wallace 1858a; also van Wyhe 2002), which introduces the three papers to be read, describes the first as follows:

1. Extracts from a MS. work on Species*, by Mr. Darwin, which was sketched in 1839, and copied in 1844, when the copy was read by Dr. Hooker, and its contents afterwards communicated to Sir Charles Lyell. The first Part is devoted to 'The Variation of Organic Beings under Domestication and in their Natural State;' and the second chapter of that Part, from which we propose to read to the Society the extracts referred to, is headed, 'On the 
Variation of Organic Beings in a state of Nature; on the Natural Means of Selection; on the Comparison of Domestic Races and true Species.'

* This MS. work was never intended for publication, and therefore was not written with care. - C. D. 1858

This is an odd and ill-focused introduction to the first paper that was actually read at the meeting. This first Darwin 'paper' was a complete section from the second chapter of his 1844 essay, the section entitled On the natural means of selection. It is a single extract, not 'extracts', and it is not named explicitly in this introductory letter. Its name occurs only as part of the chapter title on a par with the other section names that comprise this overall title.

This first 'paper' was Minuted (Darwin and Wallace 1858b) as:

(1) An 'Extract from a MS. work on Species, by Charles Darwin, Esq., F.R.S., F.L.S., \&c., sketched in 1839 and copied in 1844.'

and introduced in the Linnean Society Journal (Darwin and Wallace 1858a) (also van Wyhe 2002) as:

I. Extract from an unpublished Work on Species, by C. DARWIN, Esq., consisting of a portion of a Chapter entitled, 'On the Variation of Organic Beings in a state of Nature; on the Natural Means of Selection; on the Comparison of Domestic Races and true Species.'

Why did the letter not state 'extract' (as indeed the Minutes and published version do)? And why mention, and fully name, the first chapter (which the published introduction to this 'paper' selectively omits)? This first chapter appears to be no more relevant to the excerpt presented than the other eight chapters, which fail to get any mention whatsoever. By the time it was sent for printing (28 July as the ledger records) the imprecisions in the original letter had been eliminated.

One reason for the original confusion could be that the letter writer was unsure of what exactly would be read from this 230-page essay. Further support for such uncertainty in the mind of the letter writer is the reference to 'extracts referred to'. There are no 'extracts referred to' unless it is the earlier 'extracts from a MS. work on species'? At best, this looks like a circumlocution, adding nothing yet masquerading as a specific reference.

In addition, this letter makes some bold and debatable claims, such as: 'neither of them having published his views' and 'both authors having now unreservedly placed their papers in our hands.' Wallace had published on this general topic (Wallace 1855), and was effectively incommunicado in the Far East, his letter had (apparently) merely asked Darwin to show his paper to Lyell.

The letter writer also appears to be ignorant of the details of Darwin's theoretical development from his first writings on species transmutation (1839, 1842 and 1844) to his then current notes for his planned 'big Species book'. Or, the author is again quite unconcerned about making knowingly exaggerated claims for the constancy of Darwin's ideas. For example, the letter (Darwin and Wallace 1858a; also van Wyhe 2002) introduces the second Darwin 'paper' as: 
2. An abstract of a private letter addressed to Professor Asa Gray, of Boston, U.S., in October 1857 , by Mr. Darwin, in which he repeats his views, and which shows that these remained unaltered from 1839 to 1857.

At the 1908 Darwin-Wallace medal celebrations, the President of the Linnean Society, Dr. Dukinfield H. Scott, was a good deal more cautious about the provenance of Darwin's theory. He stated that Darwin 'had been preparing [it] during the previous 20 years' (Darwin Online, RECORD 1908).

Even Francis Darwin (who was, in general, his father's enthusiastic champion) was provoked to correct the dates that his father advanced. He pointed out that although his father had written 'This was sketched in 1839' across the contents page of the 1844 essay, and 'again in a letter to Mr. Wallace (Jan. $25^{\text {th }} 1859$ ) he speaks of his own contributions to the Linnean paper of July 1, 1858 as "written in 1839, now just twenty years ago". This statement as it stands is undoubtedly incorrect.'(Darwin 1909) According to Francis Darwin even 1842 as the effective date of the 1844 essay 'must, I think, be rejected'.

In subsequent years, a new wave of historians have documented how Darwin's theorizing on species transmutation, beginning in 1839, developed through a succession of more-or-less radical transformations (Stauffer 1975; Browne 1983). For example, Ospovat's detailed study of the development of Charles Darwin's ideas states that 'Darwin's revised theory had ... [its] roots in his speculations of the 1830s and 1840s'. In Ospovat's view a 'transformation occurred' in 'the second half of 1856' (Ospovat 1981). It was based on re-assessments of: what causes variations; how much variation occurs in nature; whether important parts vary; and the necessity for geographical isolation.

One might well dispute some aspects Ospovat's characterization of Darwin's theory development, but to claim it has 'remained unaltered from 1839 to 1857 ' flies squarely in the face of much evidence. Hooker was well aware of the details of Darwin's progress towards his 1857 summary; Lyell was much less well-versed in the details of its progression. Finally, the signatures on the letter are first that of Sir Charles Lyell followed by that of Joseph Hooker.

The conclusion forwarded is that the letter of transmittal could not have been written by the person who supervised the preparation of Darwin's excerpts for presentation because of the inaccuracies with respect to the first paper. In addition, the writer was not conversant with the details of Darwin's theoretical development. Finally, he was confident enough to state extreme interpretations of the situation perhaps partly through the ignorance of detail and partly because he feared no challenges.

All in all, this is much more a picture of Lyell than of Hooker, who explicitly cast himself as 'his [i.e. Lyell's] lieutenant in the affair', in a note to Francis Darwin (1887, vol. II, p. 126). Hooker further states that 'Lyell's approval ... rather overawed the Fellows.'

However, Hooker's reminiscence of events (Hooker 1908) (admittedly 50 years later with all the implications of a distant memory coloured by convenience) includes his request to Darwin to 'send certain papers for which I had asked as essential for completing the prefatory statement to the communication to the Linnean Society of his and Wallace's Essays.' This could carry the implication that Hooker expected to prepare the letter of transmittal, 'the prefatory statement', and only this letter? This 
inference, however, is at odds with other contemporary evidence; see, for example, Darwin's letters (below). Perhaps the overall rush of events meant that this expectation was not realized, or was it just an ill-phrased or a miss-remembered recollection. Or perhaps he needed Darwin's papers (i.e. final choice of extracts) in order to prepare fair copies for the Linnean meeting, and to communicate to Lyell the details required for the letter of transmittal if so, I assume the message passed on was not a total success.

Darwin's letter of the evening of 29 June stated that he was sending Hooker 'the papers at once' as requested. In a subsequent letter of 13 July he thanks Hooker for the arrangements concluded and Mrs Hooker for undertaking the copying of his 'ugly MS'. It seems clear that Hooker supervised the preparation of Darwin's contributions, and even selected the excerpt from the 1844 essay, contrary to Darwin's wishes (Partridge 2015).

The chosen title for the joint contribution is, as Costa (2014, p. 178) puts it: 'confusing, seemingly at odds with the actual content of the Wallace and Darwin papers.' This title - On the tendency of Species to form Varieties; and on the Perpetuation of Varieties and Species by Natural Means of Selection - misses the essential point of all three papers, which is 'the proposed mechanisms by which new species are formed.' Costa speculates that it may have been chosen as 'less incendiary than one proclaiming transmutation', and indeed it may have been, although Lyell (as mentioned above) was not known for timidity in declaring his scientific beliefs.

But if Lyell alone devised this title when constructing the letter of transmittal, we might alternatively speculate that he, who was at this juncture far from completely sold on the idea of species transmutation, just could not bring himself to baldly proclaim it. In a letter some 6 months after the event (25 January 1859) Darwin wrote to Wallace that Lyell 'is somewhat staggered [by their theory of evolution], but does not give in' (Darwin 1887, vol. II, p. 146). In a letter dated 23 September, Darwin wrote that Lyell 'is wavering so much about the immutability of species, that I expect he will come round.' (Darwin 1887, vol. II, p. 168) But, much to Darwin's disappointment, in late 1863 Lyell could still write in his Antiquity of Man: 'If it should ever be rendered highly probable that species change by variation and natural selection ...' (Darwin 1887, vol. III, p. 8, Darwin's emphasis not Lyell's).

So, years later, and still unable to commit in print to a firm belief in natural selection as the species-generating process, it is perhaps not at all surprising that on 30 June 1858 he avoided having to put his name to a letter announcing just this vision. The chosen title for the Darwin-Wallace presentation can then be seen as a hedge, perhaps for the benefit of his friend Darwin as much as for himself. By minimizing the headline claim, the fallout would be minimal should the theory being announced prove, on close and considered inspection, to be significantly limited, if not fatally flawed - e.g. natural selection may provide a new perspective on the manner and degree to which varieties may depart from the created species, while not eliminating all need for divinely created species (especially the human one - Lyell's main concern).

As a consequence of the totality of the foregoing considerations, I infer that Lyell alone composed the transmittal letter on 30 June and signed it. Hooker may have received 'the papers' from Darwin late in the night of 29 June, or perhaps not before the morning of 30 June given the hours of travel time across rural Kent to Kew in London. We know only that the journey (presumably on horseback) did not begin before the evening of 29 June. On 
30 June Hooker must have been busy finalizing and supervising his wife's copying of one (probably both) of the two excerpts from Darwin's works.

Once the letter and the individual papers had been prepared, and the oddities and inaccuracies (which Hooker, as a long-term reader and critic of Darwin's developing ideas, would have been alive to), not to mention the over-stated claims, became apparent, why was the letter not corrected, or re-written? Perhaps no adjustments were made because by the time that these two components of the presentation were brought together and the inaccuracies became apparent, it was too late?

It is, of course, quite possible that either Lyell or Hooker could have sent his own contribution to the other across London on 30 June (if we rule out a meeting as per Hooker's 1908 claim, see below). In which case, Lyell sending the transmittal letter to Hooker for his signature seems the more plausible action. But the two were to meet the next day at Burlington House at the Linnean Society, so why bother just for a signature? In an admittedly frantic period, no amount of further rush was going to get the papers read before the evening of 1 July.

Consolidation and submission of the papers on 1 July rather than 30 June supports this viewpoint. Because if the package, consisting of letter and papers, had been consolidated on 30 June, why wait until the following day to submit them, and yet not, for example, at least correct and properly focus the introduction to Darwin's first contribution?

Bearing directly on this issue we have the statement by Hooker (1908) that the only meeting between himself, Lyell and Darwin during the 13 days was between him and Lyell at the Linnean on the evening of 1 July before the Linnean meeting. Brackman (1980), however, singles out several of Hooker's claims in this address as inaccurate, and therefore calls its overall reliability into question (as we have done with respect to his request to Darwin). Nevertheless, the claim of a single, eleventh hour meeting is a simple, unequivocal statement. It offers no scope for interpretation, there is no contemporary contrary evidence, and it does fit in with the evidence and implications to contribute to a coherent overall picture.

However, Lyell in his 10th (and first post-Linnean-meeting) edition of his Principles of Geology wrote of Wallace's paper 'The Author [i.e. Wallace] requested Mr. Darwin to show this essay to me should he think it sufficiently novel and interesting. It was brought to me by Dr. Hooker' (Lyell 1868) (my emphasis). He continues with a wildly inaccurate description of Darwin's contribution to the 1 July meeting. If he can state these simple and easily verifiable facts erroneously, why should we attach significance to his otherwise conflicting evidence of an uncheckable (and to him presumably insignificant) event - the means by which he received Wallace's paper? Darwin's 18 June letter to Lyell stated that Wallace's 'MS' was enclosed.

Was it at this truly eleventh hour that Hooker appended his signature to the letter and the complete package was delivered to Bennett, the Linnean Society Secretary, who then bumped Bentham's paper off the emerging agenda and replaced it with the Darwin-Wallace papers? It was too late to alter anything, so the ill-matched letter and papers had to be delivered as they were. In 1858, a quite literally last-minute submission was possible because there was no prior agenda for meetings. As Gage and Stearn put it in their Bicentenary History of the Linnean Society: 'For more than the first 100 years of the 
Society's life members received no information of what papers were to be read at a General Meeting' (Gage and Stearn 1988, p. 135).

This proposed state of affairs also matches the fine details that can be inferred from the Linnean ledger: if the pile of received papers was entered in a top-down manner (i.e. last received is first entered, and so on down the pile) then the Darwin-Wallace papers were the very last to be received on 1 July. The three entries following those of the Darwin and Wallace papers, i.e. numbers 1249, 1250 and 1251, are also recorded as received on 1 July. And this appears to complete the batch entered because the following paper, 1252, is recorded as received on 2 August (i.e. after the earlier entries had been sent for printing). The first two of these papers, numbers 1249 and 1250, were also read at the 1 July meeting (items 2 and 4 on the agenda in the subsequent Minutes). The third and (by assumption) the first received of the 1 July batch is the Bentham paper which, according to Bentham's account of 1882, 'had to give way to Mr. Darwin's' (Darwin and Seward 1903) paper. Alternatively, of course, this 1 July batch was not entered into the ledger until sometime after the meeting, and the entry order is a simple reflection of the order in which they were read, plus the Bentham paper which was not read.

Nevertheless, we can read into these details further support for the last-minute submission of the Darwin-Wallace agenda item. First, that submission on the day of the meeting was not at all unusual. More than half the papers surveyed in the 7-year period were received on the day of the meeting at which they were read.

Second, this meeting was unusual in at least two respects. It was Minuted as a 'Special Meeting' necessitated by the death of Council Member Robert Brown some weeks earlier, and it was also an inordinately long meeting. Counting the Darwin-Wallace package (Minuted as item 1) as three papers and adding the other five Minuted items, we have eight papers read on 1 July. The average numbers of papers per meeting for the period surveyed was nearly three. Gage and Stearn (1988) report that there was a particularly 'energetic' period 'from 1853 to 1888, when the average figure for papers read at meetings is more than three.' (p. 157).

Bentham, who also submitted his paper on 1 July expecting it to be read that evening, later wrote of the 1 July meeting that 'a long paper of mine was set down for reading' (Darwin and Seward 1903). It was therefore not 'bumped' until sometime later that day. Was Bentham persuaded (or just selected) 'to give way' (rather than any of the other five contributors, two of whom also submitted their papers on 1 July) because he, who was to be elected as a Member of the Council and Vice-president for the coming year at the meeting (the latter motion moved by Lyell), would be the least put out? Or was omission of his 'long paper' simply the easiest way to significantly shorten the meeting? Whatever the reason and despite the burgeoning amount of scientific business, his, and only his, paper was a casualty of the hasty, late agenda rearrangement on 1 July. It was a re-organization that perhaps did not happen until the last-minute arrival of the Darwin-Wallace package.

Third, accepting the weak basis for our order-of-entry assumption, the fact that the Darwin-Wallace papers are listed first in the 1 July batch entries implies that they were the last papers submitted that day. This admittedly weak inference does gain some independent strengthening from the events surrounding Bentham's paper: submitted 1 July with the expectation to be read 1 July but bumped by the Darwin-Wallace 
contribution. The implicit inference here is that submission occurred first and the decision to displace it happened later, which is perhaps the most likely, but not the only possible, sequencing of these two events.

Apart from the evidence in the Linnean Society's ledger, which varies from clear-cut dates of papers received to less secure inferences of arrival times from same-date orderings, much of the above reconstruction is conjecture, as it must be when so little objective evidence exists. Nevertheless, there is a persuasive coherence in the overall picture that develops if we can accept 1 July (not 30 June) as the submission date and also accept that the letter of transmittal is revealingly imprecise.

Given the paucity of evidence, the 13 days are set to remain something of an enigma, and, given their importance to the interpretation of a major milestone in the history of science, the speculation will, no doubt, continue. This analysis makes the case that the Linnean Society's ledger provides strong support for a small, but significant, date change in the accepted narrative, and together with a re-consideration of the letter of transmittal it supports a coherent and significant restructuring of events within this important period.

\section{Acknowledgements}

Elaine Chawat, Deputy Librarian at the Linnean Society, not only first brought the Linnean's ledger to my attention, but has subsequently provided me with much useful information from it and elsewhere. She also alerted me to Glaubrecht's book on Wallace as well as provided me with some useful translation (the book is in German). Jim Moore sent me several, substantial and informative analyses of my Darwin speculations. Jeremy Black provided a similar service as did Janet Browne. George Beccaloni quickly pinpointed Brackman's unreferenced, and misdated, 1868 quotation of Lyell's that I had spent fruitless days on.

\section{Disclosure statement}

No potential conflict of interest was reported by the author.

\section{References}

Brackman AC. 1980. A delicate arrangement. New York: Times Books.

Browne J. 1983. The secular ark: studies in the history of biogeography. New Haven (CT): Yale University Press.

Browne J. 2002. Charles Darwin, the power of place. London: Jonathan Cape; p. 40.

Costa JT. 2014. Wallace. Darwin, and the origin of species. Cambridge (MA): Harvard University Press; p. 255.

Darwin C, Wallace AR. 1858a. On the tendency of species to form varieties; and on the perpetuation of varieties and species by natural means of selection. J Proc Linnean Soc London Zool. 3:45-62.

Darwin C, Wallace AR. 1858b. Proceedings of the Linnean society of London, November 5th, 1857, to July 1st, 1858 In Proceedings of the Linnean Society of London, Vol. 70, 1, p. Iv.

Darwin F, editor. 1887. The life and letters of Charles Darwin. 3 vols. London: John Murray.

Darwin F, editor. 1909. The Foundations of the Origin of Species. Cambridge: Cambridge University Press; p. xvii.

Darwin F, Seward AC, editors. 1903. More letters of Charles Darwin. Vol. 2. New York: Appleton; p. 294. 
Darwin Online, RECORD. 1908. The Darwin-Wallace celebration held on Thursday, 1st July, 1908 by the Linnean society of London. London: Printed for the Linnean Society.

Desmond A, Moore J. 1992. Darwin. London: Penguin; p. 470.

Gage AT, Stearn WT. 1988. A bicentenary history of the Linnean society. London: Academic Press; p. 56. Glaubrecht M. 2013. Am Ende des Archipels: Alfred Russel Wallace. Berlin: Galiani.

Hooker JD. 1908 Hooker's medal acceptance address, Proceedings of Linnean Society WallaceDarwin Celebration 1st July 1908, pp. 12-15.

Lyell C. 1868. Principles of geology. Vol. 2, 10th ed. London: John Murray; p. 278.

Ospovat D. 1981. The development of Darwin's Theory. Cambridge: Cambridge University Press; p. 192.

Partridge D. 2015. 1 July 1858 and the 1844 essay: what Lyell and Hooker decided; and what Darwin did not want and did not know. Biol J Lin Soc. 116:247-251.

Stauffer RC, editor. 1975. Charles Darwin's natural selection. Cambridge: Cambridge University Press.

van Wyhe, J, editor. 2002. The complete work of Charles Darwin online. Available from: http:// darwin-online.org.uk/

Wallace AR. 1855. On the law which has regulated the introduction of new species. J Nat Hist Ser 2. 16:184-196. 